\title{
THE SEPARATION OF TITANIUM, CHROMIUM, ALUMINIUM, IRON, BARIUM AND PHOSPHORIC ACID IN ROCK ANALYSIS.
}

\section{By Thomas M. Chatard.*}

HaviNG to examine some magnesian silicate rocks containing, in addition to iron and aluminum, small quantities of titanium, chromium, barium and phosphoric acid, the methods for the decomposition of such rocks and the separation of their constituents were studied and compared so as to determine the most advisable manner of procedure. After repeated trials the following course, combining a number of well-known methods, has been found to be the most satisfactory.

The silica and bases are determined by the ordinary sodium carbonate fusion method, in which the hydrates of titanium, chromium, iron and aluminum, together with the phosphoric acid, are precipitated together, and, after weighing, fused with sodium bisulphate, dissolved, the small amount of silica separated, and the solution, after reduction of the ferric oxide, titrated for total iron.

To separate these oxides and at the same time to determine the barium, two grams. of the finely pulverised mineral are put into a platinum crucible or dish, moistened with water, dilute sulphuric acid (1:1) and pure strong hydrofluoric acid added in considerable excess, the vessel put on a radiator to evaporate, and stirred from time to time. When the solution is so far evaporated that fumes of sulphuric acid begin to come off, there should still be so much acid present as to form a solution or emulsion and not a paste, since the paste is liable to bake on the bottom of the vessel and form the difficulty-soluble anhydrous sulphates produced by overheating, especially when magnesia is present in quantity. At this point it is well to add a few drops of nitric acid to oxidise the ferrous oxide, and a little more bydrofluoric acid to insure the complete expulsion of the silica. The evaporation is then continued until the sulphuric acid fumes strongly and no odour of hydrofluoric acid can be detected when the solution is cooled below the point at which the sulphuric acid fumes.

About 25 c.c. of dilute hydrochloric acid (1:5) is now added, the stirring being continued, and the material is then evaporated on the water-bath until most of the hydrochloric acid has been driven off. The material is then washed into a beaker, and any residue adhering to the vessel can be removed by a few drops of hot, strong hydrochloric acid, the vessel being rubbed with a bit of paper if necessary. If the solution be very turbid it can be digested on the water-bath for some time, but ultimately it is diluted with hot water to $250-300$ c.c, allowed to stand for several hours, and then filtered.

The residue contains the barium as sulphate, and sometimes small amounts of chromite or other minerals of the same class. It is washed, ignited and thoroughly fused with sodium carbonate in a small crucible, the fused mass being then digested with hot water. The well-washed residue is dissolved on the filter with dilute 
hydrochloric acid, and this solution filtered through the same filter, which, after washing, is burned, the ash fused with a little sodium carbonate, the mass dissolved in dilute hydrochloric acid and added to the washings, which are now acidified and added to the main solution, after reduction of the chromic acid. The hydrochloric acid solution containing the barium is evaporated to a few drops to get rid of the excess of acid, diluted, the barium precipitated, and the filtrate from the barium sulphate added to the main solution.

This main solution, which should be perfectly clear and contain the iron and chromium as sesquioxides, is now made alkaline by ammonia, and the precipitate redissolved by dilute hydrochloric acid. A few drops of acetic acid are added, the liquid brought to a boil, ammonia added in very light excess, the boiling continued for a few minutes and the precipitate filtered and washed. As the sole reason for this precipitation is to get rid of the magnesia and the accumulation of other salts, the washing need not be thorough, but the filtrate must be tested and the precipitation proved complete.

The precipitate is dissolved in hot dilute hydrochloric acid. The filter after washing is burned in a large platinum crucible, into which the solution, concentrated to a small bulk, is put and evaporated on the water-bath till it becomes pasty. Just enough water is added to dissolve the salts, and then dry sodium carbonate is added in small portions, with continual stirring, till a comparatively dry mass results. This must be carefully done, for if too much soda is added at a time, and each addition is not thoroughly stirred into the mass, the after fusion is apt to be "lumpy" and unsatisfactory.

When a good excess of carbonate has thus been added, the mass is dried and gradually brought to clear fusion, which should be continued for half an hour. If lumps form, which is, however, rarely the case if lime and magnesia are absent and the foregoing directions are followed, they can be broken up by shaking the crucible with a circular motion to detatch them from its walls. When the fusion is complete, the mass is spread around the walls of the crucible and slightly cooled. A small quantity of sodium nitrate is now added, the whole rapidly fused and carefully boiled for not more than five minutes; it is then again spread over the crucible and rapidly cooled with a blast of air. The mass is boiled with water till completely disintegrated, and then filtered and washed; repeated tests have shown that the residue which contains the titanium is, when well washed, free from chromium and phosphoric acid.

The washed residue is dissolved in hot dilute hydrochloric acid, the filter burned, the ash fused with sodium bisulphate, dissolved in water and added to the solution. The titanium in this solution is separated by the excellent method of Dr. Gooch,* all the details as laid down by him being followed. I have, however, found it convenient, after the destruction of the tartaric acid by potassium permanganate, and the clearing of the solution by sulphurous acid, to add ammonia in slight excess, then at once acetic acid in excess, and boil with addition of sulphurous acid. The precipitate of titanium hydrate, mixed with some alumina, is filtered and washed with water containing sulphurous acid and a little acetic acid. It is thus freed from manganese and brought into a small compass, rendering the after work easier. Before the final precipitation of the titanium the platinum generally in the solution should be removed by hydrogen sulphide.

* Proc. Am. Acad, 12, 435 seq. (Bull. No, 27, U.S.G.S., p. 16 seq.). 
The filtrate containing the chromic and phosphoric acids is heated, and ammonium nitrate cautiously added till no further precipitation of alumina occurs. The precipitation of the alumina phosphate seems to be complete, but some alumina always remains in solution. The precipitate is allowed to settle, the supernatant liquid decanted and the precipitate washed with a solution of ammonium nitrate until the yellow tinge disappears; it is then dissolved in dilute nitric acid, and the phosphoric acid precipitated by molybdate solution.

The filtrate containing the chromic acid is acidified, boiled, neutralised with ammonia, and the chromium precipitated by freshly prepared ammonic sulphide. The precipitate, after some washing, is dissolved in hot dilute nitric acid, and, after concentration, potassium chlorate is added, the solution boiled, and finally evaporated nearly to dryness to expel the excess of acid. It is then diluted with cold water, and a saturated solution of sodium bicarbonate added in small excess, separating the last traces of alumina. After standing about three hours, the alumina is filtered and washed with moderately dilute solution of bicarbonate. The filtrate is acidified and the chromic acid reduced and precipitated by ammonium sulphide in a platinum dish, filtered, washed, redissolved to get rid of traces of alkali, reprecipitated, and finally weighed as chromic oxide.

This method, due to Baubigny, for the separation of aluminum from chromium is very good and convenient if the solution be free from iron and contain but little alumina. Careful tests have shown that if iron be present some of it always remains in solution, while if there be much alumina it is almost impossible to wash out all the chromate from the bulky precipitate with the cold solution of bicarbonate which must be used. It must also be noted in this connection that a solution of iron and chromium prepared by the Baubigny method was made ammoniacal, and it was proved that while all of the iron was precipitated, this precipitate, even after the most careful washing with hot water, contained chromium.

Although the number of details in this process may seem very great, experience has shown that none of them can be safely neglected for the purpose of shortening the work; if the whole process be carefully followed out, the results are very satisfactory, as shown by the following tests on a typical magnesian rock :-

\begin{tabular}{|c|c|c|c|c|}
\hline No. 1, & $\begin{array}{c}\text { Percentage } \mathrm{Cr}_{2} \mathrm{O}_{3} . \\
\cdot 270\end{array}$ & $\begin{array}{l}\mathrm{TiO}_{2} . \\
\cdot 46\end{array}$ & $\begin{array}{l}\mathrm{BaO} . \\
.040\end{array}$ & $\begin{array}{l}\mathrm{P}_{2} \mathrm{O}_{5} \\
\cdot 375\end{array}$ \\
\hline No. 2, & $\cdot 285$ & $\cdot 39$ & $\cdot 060$ & $\cdot 385$ \\
\hline No. 3 , & $\cdot 317$ & $\cdot 46$ & $\cdot 055$ & $\cdots$ \\
\hline No. 4, & $\cdot 280$ & $\cdots$ & $\cdots$ & .. \\
\hline Average, & $\cdot 288$ & $\cdot 44$ & .052 & $\cdot 380$ \\
\hline
\end{tabular}

The use of sodium nitrate for the fusions is not absolutely necessary, though one is more sure of complete oxidation if it be employed. In the analysis of chrome ores the best results have been obtained by fusing the flnely-pulverised ore with sodium carbonate alone, but keeping it in clear fusion for an hour. The fused mass is treated like an ordinary silicate fusion, the silica after weighing being volatilised by hydrofluoric acid, and the residue, usually small, again fused with sodium carbonate, giving a clear solution in hydrochloric acid. 